\title{
Thermoelectric Power versus Electrical Conductivity Plot for Annealing Process in Low-carbon Aluminium-killed Steel ${ }^{*}$
}

\author{
By Hideo ABE** and Takeshi SUZUKI**
}

\begin{abstract}
Synopsis
In a low-carbon aluminium-killed steel cold rolled to a reduction of 75\% in thickness, changes in the thermoelectric power and the electrical resistivity on annealing in a salt bath kept at $695^{\circ} \mathrm{C}$ have been observed. Three annealing stages are separated definitely and interpreted on the thermopower versus electrical conductivity plot at $0^{\circ} \mathrm{C}$. In the first stage the dislocation density decreases while the carbon atoms dissociated from cementite segregate to dislocations. The second stage commences when the dislocations are saturated with respect to carbon and the dissociated carbon atoms become to occupy interstitial sites of dislocation-free regions of the iron matrix. In the final third stage the cementite particles continue to dissolve into the completely recrystallized iron matrix. The gradient of the thermopower versus conductivity plot at $0^{\circ} \mathrm{C}$ characteristic to the carbon atoms trapped by dislocations is tentatively estimated to be $240 \mu \mathrm{V} \cdot \mu \Omega \cdot \mathrm{cm} \cdot \mathrm{deg}^{-1}$, which is slightly lower than that characteristic to the carbon atoms occupying the interstitial sites of the dislocation-free iron lattice.
\end{abstract}

\section{Introduction}

In a previous study ${ }^{1)}$ of cold rolling and annealing processes in pure iron it has been shown that the thermoelectric power shows a high response while the electrical resistivity shows a low response to the change in dislocation density, whereas the former shows a low response while the latter shows a high response to the changes in dissolved carbon and nitrogen contents. Therefore, the measurements of both thermopower and electrical resistivity enable us to separate various stages of annealing processes in cold worked low-carbon steels in which recovery, recrystallization and precipitation or redissolution of various carbides and nitrides take place successively or simultaneously.

In a recent study of an annealing process in a lowcarbon aluminium-killed steel, we have used both thermopower and electrical resistivity measurements, supplemented by light microscopy and hardness measurement. The present paper concerns with an interpretation of the annealing process on the absolute thermopower versus electrical conductivity plot.

\section{Experimental Procedure}

The starting material used in the present study is a hot rolled strip of a commercial low-carbon aluminium-killed steel whose chemical composition is given in Table 1. The thickness of the strip was $2.96 \mathrm{~mm}$.

A specimen, $100 \mathrm{~mm}$ long and $30 \mathrm{~mm}$ wide, cut from the strip was austenitized for $2 \mathrm{hr}$ at $920^{\circ} \mathrm{C}$ in an argon-flow tube furnace, subsequently quenched into ice-water, then annealed at $710^{\circ} \mathrm{C}$ for $2 \mathrm{hr}$ in the same furnace and slowly cooled at a rate of $25^{\circ} \mathrm{C} / \mathrm{hr}$.
The microstructure of the specimen after the above heat-treatments is as shown in Photo. 1. Most of the cementite particles are localized along grain boundaries but a few particles are embedded in the interior of ferrite grains. In view of the transmission electron micrographs observed in a similar steel, it was believed that the aluminium nitride had almost completely precipitated as that of the stable wurtzite structure.

After the above heat-treatments, the specimen was cold rolled at room temperature to a reduction of $75 \%$ in thickness. Eighteen test-pieces were prepared from the cold rolled sheet. Dimensions of the test-pieces were approximately $120 \mathrm{~mm}$ by $4 \mathrm{~mm}$ by $0.74 \mathrm{~mm}$.

Electrical resistivity measurements on these testpieces at $0^{\circ} \mathrm{C}$ and at liquid nitrogen temperature were made by the conventional four-terminal potentiometer method, the correction for the size factor being made by assuming that Matthiessen's rule for electrical resistivity approximately holds. ${ }^{2)}$ Measurements of absolute thermoelectric power at $0^{\circ} \mathrm{C}$ were made by a method similar to that described in the previous paper. ${ }^{1)}$

Each test-piece was separately immersed with stirring in a salt bath $\left(\mathrm{CaCl}_{2}: \mathrm{NaCl}: \mathrm{BaCl}_{2}: \mathrm{KCl}=\right.$

Table 1. Chemical composition (wt.\%)

\begin{tabular}{cccccccc}
\hline $\mathrm{C}$ & $\mathrm{Si}$ & $\mathrm{Mn}$ & $\mathrm{P}$ & $\mathrm{S}$ & sol. Al insol. Al & sol. N \\
\hline 0.046 & 0.01 & 0.35 & 0.020 & 0.018 & 0.030 & 0.010 & 0.0060
\end{tabular}

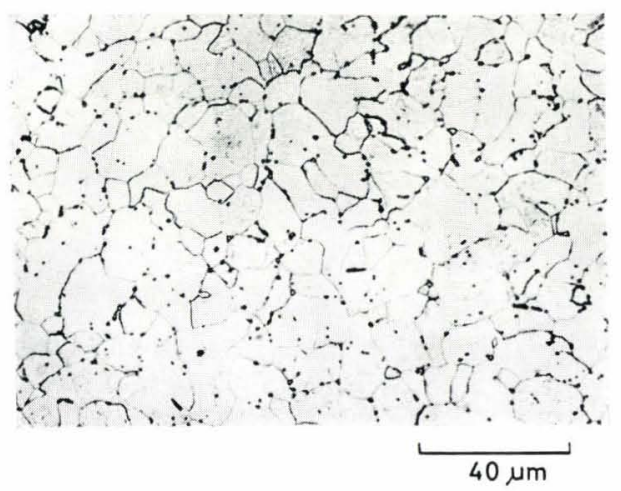

Photo. 1. Microstructure of low-carbon aluminium-killed steel specimen austenitized for $2 \mathrm{hr}$ at $920^{\circ} \mathrm{C}$, quenched into ice-water, annealed for $2 \mathrm{hr}$ at $710^{\circ} \mathrm{C}$ and slowly cooled at a rate of $25^{\circ} \mathrm{C} / \mathrm{hr}$ 
7: 14:50:29 in weight percent) kept at $695^{\circ} \mathrm{C} \pm 5^{\circ} \mathrm{C}$ for a prearranged time $(1,2,3,4,5,6,8,12,20,60$, 300,1400 or $6000 \mathrm{sec}$ ) and quenched into ice-water. According to a preliminary test on the heat transfer during the immersing, the temperatures at the middle of the thickness of a test-piece after 1, 2, 3, 4 and $5 \mathrm{sec}$ were $422^{\circ} \mathrm{C}, 619^{\circ} \mathrm{C}, 683^{\circ} \mathrm{C}, 692^{\circ} \mathrm{C}$ and $693^{\circ} \mathrm{C}$, respectively. The period of $6 \mathrm{sec}$ was long enough to heat the test-piece up to nearly $695^{\circ} \mathrm{C}$ throughout the entire thickness. Such a heating condition should be taken into consideration if necessary for the interpretation of the data obtained.

The values of electrical resistivity observed on the eighteen test-pieces before annealing showed a slight scatter $( \pm 0.3 \%)$. After excluding to the fourth highest deviation, the mean value for the fourteen test-pieces utilized was regarded as the standard electrical resistivity before annealing. The values of electrical resistivity after annealing for various times were obtained by subtracting the observed changes in resistivity from the mean value before annealing.

Hardness measurement and the determination of the fraction recrystallized by light microscopy were made on a portion of each test-piece.

In order to determine the amounts of carbon occupying the interstitial sites of dislocation-free regions of the iron matrix, all the test-pieces were additionally tempered at $250^{\circ} \mathrm{C}$ for $50 \mathrm{hr}$ and the accompanied changes in resistivity and thermopower were observed. It was assumed that the carbon atoms dissolved into the interstitial sites of dislocation-free regions of the iron matrix would precipitate almost completely as cementite during the $50 \mathrm{hr}$ tempering at $250^{\circ} \mathrm{C}$. On the other hand, the carbon atoms trapped by dislocations were assumed to be so strongly stabilized that they would not be released by tempering at $250^{\circ} \mathrm{C}$.

All the data obtained from the thermopower and the resistivity measurements at $0^{\circ} \mathrm{C}$ were plotted on the absolute thermopower versus electrical conduc- tivity graph. Such a plot has been called as the Nordheim-Gorter plot ${ }^{3)}$ which is known to show a linear relation between the electron-diffusion thermopower and the conductivity in alloys of normal metals.

\section{Results and Discussion}

The changes in the electrical resistivity at liquid nitrogen temperature, the hardness and the fraction recrystallized on annealing in the salt bath kept at $695^{\circ} \mathrm{C}$ followed by quenching are given in Fig. 1. It is evident that primary recrystallization proceeded remarkably in a period between $3 \mathrm{sec}$ and $8 \mathrm{sec}$. The increase in electrical resistivity from about $3 \mathrm{sec}$ must be due to the dissolution of cementite particles into the iron matrix. A slight increase in the hardness from about $20 \mathrm{sec}$ is also attributable to the increase in dissolved carbon content.

Figure 2 is the absolute thermopower versus electrical conductivity plot at $0^{\circ} \mathrm{C}$ for all the test-pieces annealed for various times in the salt bath kept at $695^{\circ} \mathrm{C}$ and subsequently quenched into ice-water. There are at least three annealing stages represented by the respective linear portions of the graph. The first stage is from $0 \mathrm{sec}$ to $3 \mathrm{sec}$, the second stage is from $4 \mathrm{sec}$ to $8 \mathrm{sec}$, and the final third stage commences at $12 \mathrm{sec}$.

The gradient of the straight line for the first stage is $570 \mu \mathrm{V} \cdot \mu \Omega \cdot \mathrm{cm} \cdot \mathrm{deg}^{-\mathbf{1}}$. This gradient is somewhat higher than that characteristic to the dislocation $\left(500 \pm 100 \mu \mathrm{V} \cdot \mu \Omega \cdot \mathrm{cm} \cdot \mathrm{deg}^{-1}\right)$ observed in pure iron, ${ }^{1)}$ but it may at least be said that the predominant reaction taken place during the first stage must have been the decrease in dislocation density.

The gradient of the third stage is $260 \mu \mathrm{V} \cdot \mu \Omega \cdot \mathrm{cm}$. $\mathrm{deg}^{-1}$, which is nearly equal to the value of $270 \pm$ $50 \mu \mathrm{V} \cdot \mu \Omega \cdot \mathrm{cm} \cdot \mathrm{deg}^{-1}$ characteristic to the carbon in solution observed in a similar steel. ${ }^{4)}$ Therefore, the main reaction in the third stage must have been the dissolution of cementite particles into the iron matrix.

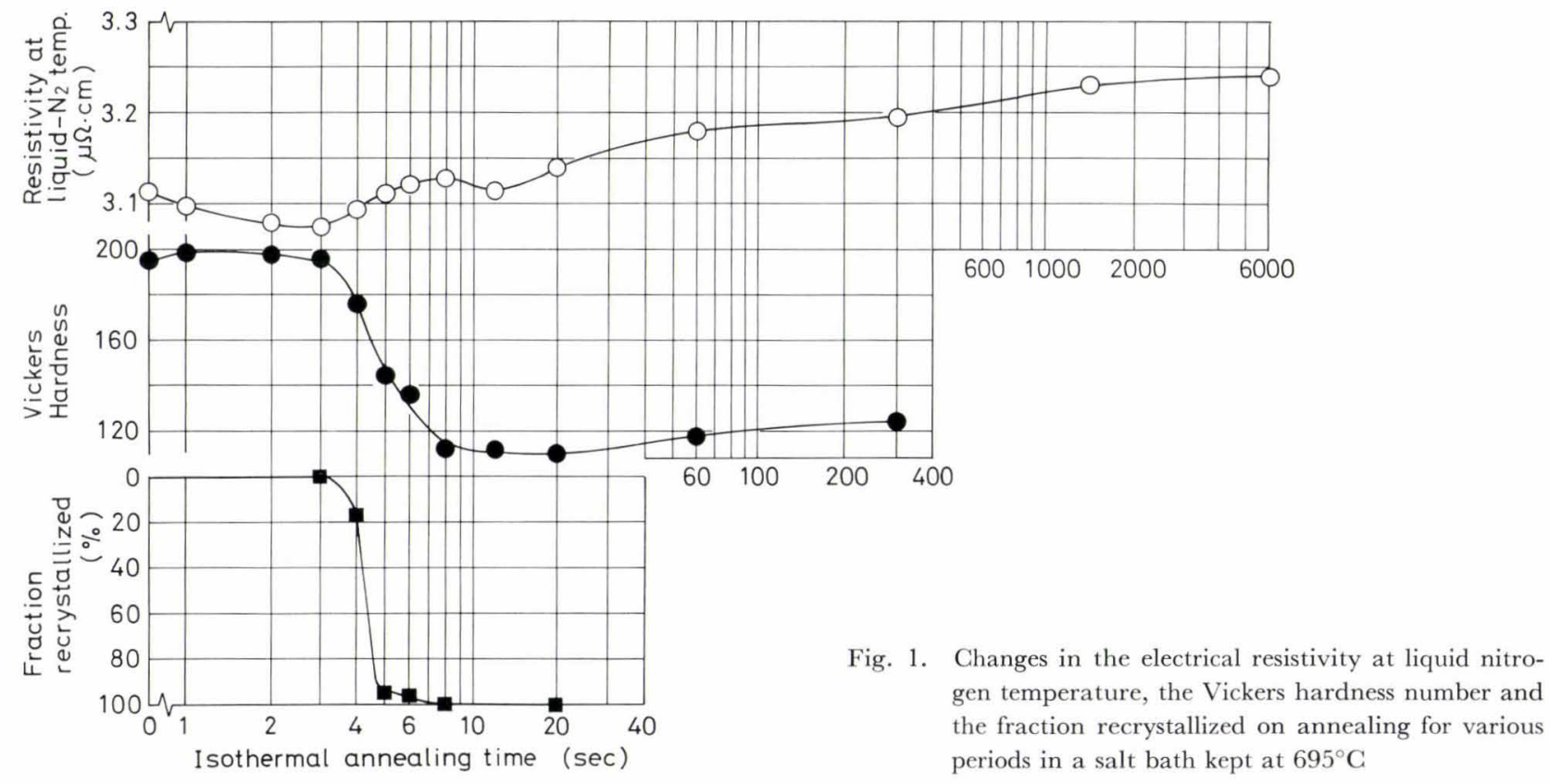


It is an unexpected fact that the gradient of the second stage is nearly equal to that of the first stage and the shift of data point in the second stage is almost in the opposite direction to that of the first stage. The interpretation of this second stage is the main purpose of the present paper.

Considering from the results shown in Fig. 1, it is obvious that the following reactions occurred on annealing in the salt bath kept at $695^{\circ} \mathrm{C}$.

1) Decrease in dislocation density by recovery and primary recrystallization.

2) Dissolution of cementite particles into the iron matrix.

Another reaction which must have occurred is the segregation of dissolved carbon atoms to dislocations. It has been known that the equilibrium concentration of carbon atoms trapped by dislocations in-

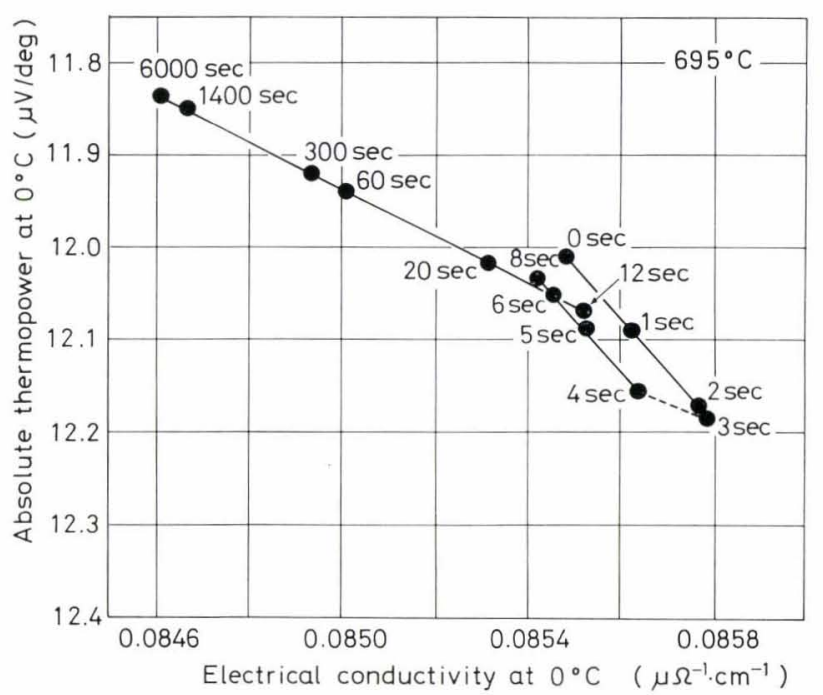

Fig. 2. The absolute thermoelectric power versus electrical conductivity plot at $0^{\circ} \mathrm{C}$ for the process of anneal ing for various periods in a salt bath kept at $695^{\circ} \mathrm{C}$ creases with decreasing the temperature of the steel. ${ }^{5,6)}$ In the present experiment, the quenching rate was not high enough (nearly $10^{3} \mathrm{deg} / \mathrm{sec}$ ) to prevent the migration of carbon atoms to dislocations during quenching. The possibility of such a reaction to occur during quenching was demonstrated by Speich ${ }^{7)}$ in the case of the martensitic transformation in carbon steels. In the present case, the test-piece annealed for $1 \mathrm{sec}, 2 \mathrm{sec}$ or $3 \mathrm{sec}$ still contained a high density of dislocations and the migration of carbon atoms to the dislocations was expected to occur during quenching.

In order to examine whether the carbon atoms had been trapped by dislocations or entered the normal interstitial sites of dislocation-free regions of the iron matrix, and to determine, if possible, the partition of carbon between the dislocation sites and the normal interstitial sites, all the quenched testpieces were tempered at $250^{\circ} \mathrm{C}$ for $50 \mathrm{hr}$. The shifts of the data points on tempering at $250^{\circ} \mathrm{C}$ are shown in Fig. 3. In this figure, the data points after annealing in the salt bath for $1 \mathrm{sec}, 2 \mathrm{sec}, 3 \mathrm{sec}$ and so forth followed by quenching are plotted by filled circles designated 1, 2, 3, etc., and the respective data points after tempering at $250^{\circ} \mathrm{C}$ for $50 \mathrm{hr}$ are plotted by open circles designated $1^{\prime}, 2^{\prime}, 3^{\prime}$, etc. Data point 0 is that immediately after cold rolling and it shifted to $0^{\prime}$ after keeping at $250^{\circ} \mathrm{C}$ for $50 \mathrm{hr}$.

The line $00^{\prime}$ has a gradient considerably higher than that of the first stage. This high gradient suggests that the predominant reaction involved was undoubtedly the decrease in dislocation density (we call it "reaction component D") but another reaction contributing to an additional increase of the gradient (we call it "reaction component $\mathrm{S}$ ") must have taken place simultaneously. In this connection, it should be noted that the gradient of line $11^{\prime}$ is still more higher, and, moreover, lines $22^{\prime}$ and $33^{\prime}$ incline further to have negative gradients. As men-

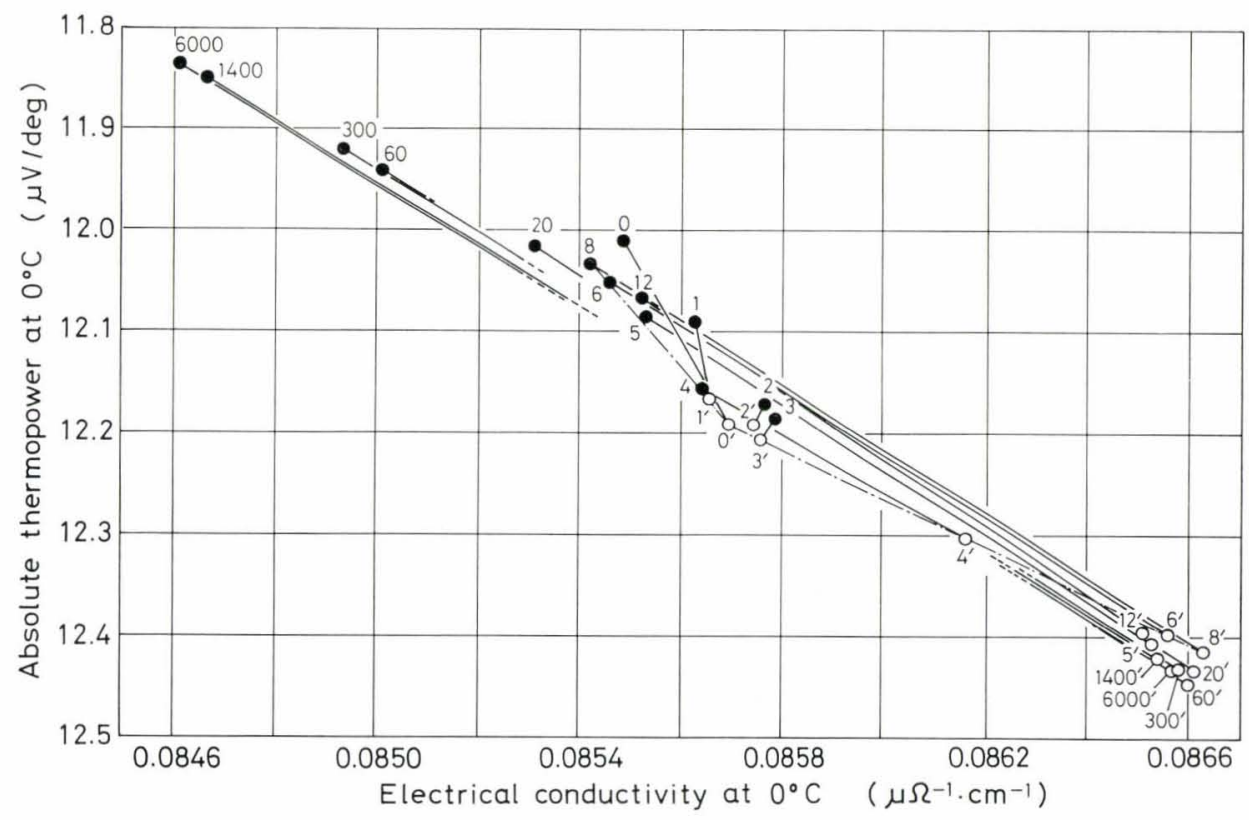

Fig. 3. Shift of data points on tempering at $250^{\circ} \mathrm{C}$ for $50 \mathrm{hr}$ 
tioned above, the thermopower versus conductivity plot shown in Fig. 2 suggests that the dislocation density gradually decreased on annealing for $1 \mathrm{sec}, 2 \mathrm{sec}$ and $3 \mathrm{sec}$. Consequently, the above-mentioned reaction component $\mathrm{D}$ in the tempering processes $0-0^{\prime}$, $1-1^{\prime}, 2-2^{\prime}$ and $3-3^{\prime}$ would have decreased in this order.

The reaction component $\mathrm{S}$ must be either the dissolution of cementite into the iron matrix or the segregation of dissolved carbon atoms to dislocations. Since the solubility of cementite in alpha iron at $250^{\circ} \mathrm{C}$ is very small (about $2.3 \mathrm{wt}$.ppm carbon according to Wert's equation ${ }^{8)}$ or about $0.8 \mathrm{wt} . \mathrm{ppm}$ carbon according to Swartz's equation ${ }^{9)}$ ), it can be practically said that the carbon atoms dissociated from cementite would directly dissolve into the dislocation sites of the iron matrix. During the tempering processes $0-0^{\prime}, 1-1^{\prime}, 2-2^{\prime}$ and $3-3^{\prime}$, almost all the carbon atoms dissociated from cementite would have been trapped by dislocations and the precipitation of carbides from the iron matrix would have scarcely occurred.

The gradient of line $00^{\prime}, 11^{\prime}, 22^{\prime}$ or $33^{\prime}$ should be interpreted on the basis of an idea that vector $\overrightarrow{00^{\prime}}$, $\overrightarrow{11^{\prime}}, \overrightarrow{22^{\prime}}$ or $\overrightarrow{33^{\prime}}$ must be a sum of the component vectors; one corresponding to reaction component D and another corresponding to reaction component $\mathrm{S}$. For the present, we cannot derive a unique quantitative solution since the gradient for the reaction $\mathrm{S}$ is unknown.

In view of the results shown in Fig. 1 it is obvious that, on annealing for $4 \mathrm{sec}$ followed by quenching, the dislocation density markedly decreased with the advancement of primary recrystallization while the dissolution of cementite still continued. As a consequence, the dislocations must have been saturated with respect to carbon and only a fraction of the dissociated carbon atoms would have been allowed to segregate to the dislocations. The excess free carbon atoms would have become to occupy the interstitial sites of dislocation-free regions of the iron matrix after quenching. Consequently, the shift of data point from 4 to $4^{\prime}$ on tempering at $250^{\circ} \mathrm{C}$ can be supposed to be as due to the precipitation of cementite from the dislocation-free regions of the iron matrix. The decrease in electrical resistivity during this shift is $0.069 \mu \Omega \cdot \mathrm{cm}$. It corresponds to $23 \mathrm{wt} . \mathrm{ppm}$ carbon having occupied the interstitial sites provided that the electrical resistivity contribution of dissolved carbon is $29.5 \mu \Omega \cdot \mathrm{cm} / \mathrm{wt} . \%{ }^{7)}$

On annealing for $5 \mathrm{sec}$ or longer, the primary recrystallization draws to a close. Then, almost all the carbon atoms would occupy the interstitial sites of dislocation-free areas of the recrystallized iron matrix and precipitate as cementite on tempering at $250^{\circ} \mathrm{C}$. From the decreases in resistivity on tempering at $250^{\circ} \mathrm{C}$ for $50 \mathrm{hr}$, the amounts of carbon having occupied the interstitial sites after annealing for 5, 6 and $8 \mathrm{sec}$ followed by quenching are estimated to be 46, 50 and 56 wt.ppm, respectively.

The predominant reaction occurred during annealing within the period from $5 \mathrm{sec}$ to $6000 \mathrm{sec}$ will be the dissolution of cementite into the recrystallized iron matrix. Any discontinuity in this reaction cannot be expected to occur, whereas the plot shown in Fig. 2 clearly reveals an abrupt change in gradient at around $8 \mathrm{sec}$ or $12 \mathrm{sec}$, when the primary recrystallization has just come to an end. As mentioned earlier, the gradient of the third stage is undoubtedly that characteristic to the dissolution of cementite. Then, we must seek after the reason of the steep gradient of the second stage.

It must be pointed out that data points $3^{\prime}, 4^{\prime}, 6^{\prime}$ and $8^{\prime}$ can approximately be fitted to a straight line with a gradient of $240 \mu \mathrm{V} \cdot \mu \Omega \cdot \mathrm{cm} \cdot \mathrm{deg}^{-1}$. This line may be regarded to correspond to the decrease in the density of "carbon-deposited dislocations" because the carbon atoms trapped by dislocations must have not been released during the $50 \mathrm{hr}$ tempering at $250^{\circ} \mathrm{C}$. This gradient of $240 \mu \mathrm{V} \cdot \mu \Omega \cdot \mathrm{cm} \cdot \mathrm{deg}^{-1}$ may be defined to be that characteristic to the "carbondeposited dislocations " or, in an inversed statement of the same meaning, "the carbon atoms trapped by dislocations.'"

It should be also noted that the extension of the straight line connecting data points $8,6,5$ and 4 and that of the straight line connecting data points $8^{\prime}, 6^{\prime}$, $4^{\prime}$ and $3^{\prime}$ cross each other at a point which nearly coincides with data point $0^{\prime}$. Here, the cross point is also designated $0^{\prime}$ for convenience, though the physical meanings for these two points may not necessarily be the same. By vector representation

$$
\overrightarrow{0^{\prime} 8}=\overrightarrow{0^{\prime} 8^{\prime}}+\overrightarrow{8^{\prime} 8}=\overrightarrow{0^{\prime} 8^{\prime}}-\overrightarrow{88^{\prime}}
$$

Where, $\overrightarrow{0^{\prime} 8^{\prime}}$ means the decrease in the density of carbon-deposited dislocations and $\overrightarrow{88^{\prime}}$ means the precipitation of cementite from the dislocation-free iron matrix at $250^{\circ} \mathrm{C}$. Vector $\overrightarrow{8^{\prime} 8}=-\overrightarrow{88^{\prime}}$ means a reverse reaction of $\overrightarrow{88^{\prime}}$, that is, the dissolution of cementite into the dislocation-free iron matrix. Then, it is concluded that vector $\overrightarrow{0^{\prime} 8}$ means a composite process that consisted of (1) the decrease of carbon-deposited dislocations and (2) the dissolution of cementite into the dislocation-free iron matrix. The second stage is thus interpreted as due to such a composite process. It can be concluded that the steep gradient of the second stage is caused by the vector component that corresponds to the decrese of the carbon-deposited dislocations.

However, there remains a question why the gradient of the third stage (about $260 \mu \mathrm{V} \cdot \mu \Omega \cdot \mathrm{cm} \cdot \mathrm{deg}^{-1}$ ), which is also considered to be that corresponds to the dissolution of cementite, differs from that of vector $\overrightarrow{8^{\prime} 8}$ (about $310 \mu \mathrm{V} \cdot \mu \Omega \cdot \mathrm{cm} \cdot \mathrm{deg}^{-1}$ ). An answer to this question is as follows. The precipitation of cementite at $250^{\circ} \mathrm{C}$ induces coherency strains together with an array of defects along the semicoherent precipitate-matrix interface. The solute carbon atoms will be either rearranged in the strain fields or trapped by the defects. These interactions act to eliminate the tetragonal strains of the iron lattice around each interstitial carbon atom. Thus, vector $\overrightarrow{88^{\prime}}$ will contain a component corresponding to the 
elimination of the tetragonal strains. On the other hand, the gradient of the third stage will be that characteristic to the dissolution of " incoherent cementite particles" into the dislocation-free iron matrix, in which naturally the contribution of the tetragonal strains is included.

For a more strict analysis of the plot, therefore, the effect of the tetragonal strains should be taken into consideration. Further research work is required to determine the gradient characteristic to the tetragonal strains, which has been a main interest in our recent work on the thermopower of the tetragonal martensite in an eutectoid carbon steel. ${ }^{10)}$

If vector $\overrightarrow{88^{\prime}}$ contains the component of the elimination of the tetragonal strains, the gradient of $\overrightarrow{0^{\prime} 8^{\prime}}$ would also be influenced by this component. In this sense, the value of $240 \mu \mathrm{V} \cdot \mu \Omega \cdot \mathrm{cm} \cdot \mathrm{deg}^{-1}$ for the carbon atoms trapped by dislocations may be a tentative one. At present, we know too little to carry out this process of discussion in detail.

\section{Summary}

A low-carbon aluminium-killed steel specimen in which both aluminium nitride and cementite had almost completely precipitated was cold rolled to a reduction of $75 \%$ in thickness, annealed for various times in a salt bath kept at $695^{\circ} \mathrm{C}$ and quenched into ice-water. Three stages of the annealing process were separated definitely and interpreted on the thermoelectric power versus electrical conductivity plot at $0^{\circ} \mathrm{C}$.

In the first stage the dislocation density decreased while the carbon atoms dissociated from cementite were trapped by the dislocations. In the second stage the dislocation density markedly decreased by recrystallization. As a consequence, the dislocations were saturated with respect to carbon and the dissociated carbon atoms became to occupy the interstitial sites of dislocation-free regions of the iron matrix. In the final third stage the cementite particles continued to dissolve into the completely recrystallized iron matrix.

The gradient of the thermopower versus conductivity plot at $0^{\circ} \mathrm{C}$ characteristic to the carbon atoms trapped by dislocations was tentatively estimated to be $240 \mu \mathrm{V} \cdot \mu \Omega \cdot \mathrm{cm} \cdot \mathrm{deg}^{-1}$ slightly lower than the value of $260 \mu \mathrm{V} \cdot \mu \Omega \cdot \mathrm{cm} \cdot \mathrm{deg}^{-1}$ characteristic to the carbon atoms occupying the normal interstitial sites of the dislocation-free iron lattice.

\section{REFERENCES}

1) H. Abe, T. Suzuki and H. Hoshina: Tetsu-to-Hagané, 65 (1979), 399.

2) J. Takamura, I. Takahashi and M. Amano: Trans. ISIJ, 9 (1969), 216

3) L. Nordheim and C. J. Gorter: Physica, 2 (1935), 383.

4) H. Abe, T. Suzuki and O. Furukimi: Tetsu-to-Hagané, 63 (1977), 971.

5) W. Köster, L. Bangert and R. Hahn: Arch. Eisenhüttenw., 25 (1954), 569.

6) K. Kamber, D. Keefer and C. Wert: Acta Met., 9 (1961), 403.

7) G. R. Speich: Trans. Met. Soc. AIME, 245 (1969), 2553.

8) C. A. Wert: Trans. AIME, 188 (1950), 1242.

9) J. C. Swartz: Trans. Met. Soc. AIME, 239 (1967), 68 \& 245 (1969), 1083.

10) H. Abe, T. Suzuki and H. Hoshina: Tetsu-to-Hagané, 63 (1977), S331. 